\title{
CORE (OES
}

CIÊNCIA E TECNOLOGIA

\section{ELABORAÇÃO E CARACTERIZAÇÃO DE MOUSSE DE SIRIGUELA (SPONDIAS PURPUREA) ADICIONADO DE PÓLEN APÍCOLA}

\author{
RENATA CHASTINET BRAGA ${ }^{1}$, LORENA LIGIA DE LIMA MONTEIRO ${ }^{1}$, KIVIA KELLY BEZERRA DO \\ NASCIMENTO ${ }^{1}$, FLANNIA MARIA RABELO E SILVA ${ }^{1}$, ARIOSVANA FERNANDES LIMA ${ }^{1}$ \\ ${ }^{1}$ Instituto Federal de Educação, Ciência e Tecnologia do Ceará (IFCE) \\ $<$ rchastinet@ifce.edu.br $><$ lorenaligialima@gmail.com $><$ kiviakellynutri@gmail.com $><$ marlinhamn@hotmail. \\ com><vana@ifce.edu.br $>$ \\ DOI: $10.21439 /$ conexoes.v13i5.1817
}

\begin{abstract}
Resumo. O mercado de alimentos funcionais no Brasil vem crescendo, porém ainda é mínimo quando comparados a países como Japão e estados Unidos. Há a necessidade da criação de outros produtos inovadores, capazes de agregar valor nutricional a partir de suas propriedades funcionais, tendo em vista a crescente demanda por esses produtos no mercado atual. O objetivo deste trabalho é elaborar e caracterizar a mousse de siriguela adicionado de pólen apícola visando a criação de um produto funcional. Foi feito um trabalho experimental de elaboração de formulações de mousse de siriguela com diferentes concentrações de pólen apícola. Foram feitos a composição centesimal, avaliações físico-químicas de PH, Vitamina C, acidez e compostos fenólicos e o perfil de textura. Os resultados demonstraram alto teor de umidade $(70,43$ a $71,20)$ e caboidratos $(20,62$ a 21,36 ) e teores de proteina de 1,83 a $2,43 \%$, lipídios 4,83 a 5,45 , e cinzas de 0,90 a $0,92 \%$. Sem variações significativas para o valor calórico. Os resultados de compostos fenólicos e vitamina $\mathrm{C}$ indicaram que a adição do pólen apícola promoveu o aumentos dos composto bioativos. Com relação ao perfil de texturas a coesividade e mastigabilidade apresentação mudanças significativas, portanto conclui-se que a adição do pólen apícola a mousse gera um produto com potencial de alimento funcional pela presença de composto fenólicos e vitamina $\mathrm{C}$, mas são necessários teste sensoriais de aceitação, principalmente ligadas aos aspectos textura e sabor para que ele seja disponibilizado para o mercado.
\end{abstract}

Palavras-chave: Biotivos. Alimentos Funcionais. Perfil de Textura.

\section{PREPARATION AND CHARACTERIZATION OF MOUSSE OF SIRIGUE- LA (SPONDIAS PURPUREA) ADDED FROM BEE POLLEN}

\begin{abstract}
The functional food market in Brazil has been growing, but it is still minimal when compared to countries like Japan and the United States. There is a need to create innovative products, capable of adding nutritional value from their functional properties, in view of the growing demand for these products in the current market. The goal of this work is to elaborate and characterize the siriguela mousse added with bee pollen aiming at the creation of a functional product. Experimental work was carried out to develop formulations of siriguela mousse with different concentrations of bee pollen. The centesimal composition, physicochemical evaluations of $\mathrm{PH}$, Vitamin $\mathrm{C}$, acidity and phenolic compounds and texture profile were made. The results showed high moisture content (70.43 to 71.20$)$ and cabohydrates (20.62 to 21.36 ) and protein contents of 1.83 to $2.43 \%$, lipids 4.83 to $5.45 \%$, and ashes from 0.90 to $0.92 \%$. No significant variations in caloric value. The results of phenolic compounds and vitamin $\mathrm{C}$ indicated that the addition of bee pollen promoted the increase of bioactive compounds. Regarding the texture profile the cohesiveness and chewability show significant changes, therefore it is concluded that the addition of bee pollen to mousse generates a product with functional food potential by the presence of phenolic compounds and vitamin C, but sensory acceptance tests are required. , mainly linked to the texture and flavor aspects to make it available to the market.
\end{abstract}

Keywords: Bioactive. Functional foods. Texture Profile. 


\section{INTRODUÇÃO}

É crescente a exigência por alimentos de boa composição nutricional que possam oferecer benefícios à saúde. O uso de polpas de frutas, por exemplo, tem sido amplamente utilizado na elaboração de novos produtos tendo em vista a potencialidade de nutrientes e demais compostos contidos na mesma (MARUYAMA et al., 2006; BATAGLION et al., 2015).

As sobremesas lácteas prontas para o consumo como mousse tem ganhado mercado por serem opções interessantes do ponto de vista funcional, nutritivo e sensorial, servindo ainda como matriz para incorporação de frutas ou polpas de frutas, enriquecendo assim o produto e sua funcionalidade (BURITI; BEDANI; SAAD, 2016).

Spondia purpurea L. (siriguela) da família Anacardiaceae é originária da América Central, está distribuída desde o México até o norte do Peru e do Brasil, apresenta-se endêmica em regiões com clima semiárido (TEXEIRA et al., 2007). A seriguela é conhecida também como ameixa-da-espanha, cajá vermelho, ciroela, jocote, ciruela mexicana, essa espécie apresenta variações de cor vermelho, amarelado e sabor ácido a doce sendo classificada como uma fruta rica em compostos fitoquímicos, apresentando um teor elevado de antioxidantes, compostos fenólicos e carotenoides, podendo ser combinado com diversos outros ingredientes (ENGELS et al., 2012).

Entende-se por pólen apícola o resultado da aglutinação do pólen das flores, efetuada pelas abelhas operárias, mediante néctar e suas substâncias salivares, o qual é recolhido no ingresso da colmeia (BRASIL, 2001).

O pólen (do grego "pales" = farinha ou pó) das flores é o conjunto dos elementos reprodutores masculinos das mesmas, no qual se encontram os gametas que irão fecundar os óvulos para posteriormente gerar sementes. É composto por uma grande proporção de proteínas $(16$ a $40 \%)$ de alto valor biológico (contém todos os aminoácidos essenciais), assim como numerosas vitaminas, principalmente $\mathrm{C}$ e $\mathrm{B} 3$ (XIMENES; COSTA; NASCIMENTO, 2011).

Segundo Carpes et al., (2008) o pólen apícola apresenta nutrientes importantes como carboidratos, proteínas, aminoácidos, lipídios, vitaminas e minerais, além de carotenoides, flavonoides e fitosteróis, sendo assim bastante utilizado como alimento alternativo ou suplementação alimentar.

Devido à demanda comercial, a produção de pólen apícola aumentou nos últimos anos e a abelha (Apis melífera) destaca-se como a melhor fornecedora deste produto (BARTH et al., 2010).

Nos últimos anos tem-se observado o aumento do surgimento de novos alimentos no mercado a partir dos crescentes estudos sobre a relação dieta e saúde. Os alimentos funcionais vêm ganhando espaço no mercado consumidor. Por se tratar da incorporação de ingredientes bioativos a alimentos que contém pouca ou nenhuma quantidade, esses não são utilizados para o tratamento de doenças, mas podem reduzir o risco delas. Os alimentos funcionais têm como objetivo reforçar a dieta com substâncias cujo efeito não é suficiente na dieta habitual (BRAGA; BARLETA, 2017; BALDISSERA et al., 2011).

Assim, a necessidade da concepção de produtos inovadores, capazes de agregar valor nutricional pelas suas propriedades funcionais, tendo em vista a crescente demanda por esses produtos no mercado atual faz aumentar os benefícios da incorporação do pólen a polpa de seriguela, como o aumento no potencial antioxidante do produto, melhora no perfil proteico e teor de fibras, além de agregar sabor ao mesmo. Com isso, o presente estudo objetivou elaborar e caracterizar físico-quimicamente um mousse de seriguela adicionado de pólen apícola.

\section{MATERIAIS E MÉTODOS}

\subsection{Caracterização do Estudo e Material}

Trata-se de um estudo experimental, com características descritivas e analíticas. Experimental, pois será elaborado um produto com características próprias, e descritivo e analítico porque será descrito e avaliado todo o processo e execução do produto.

A pesquisa foi realizada no Instituto Federal de Educação, Ciência e Tecnologia do Ceará Campus Limoeiro do Norte CE. As formulações e análise dos mousses foram realizadas na Planta Piloto de frutos e hortaliças e laboratório de química e bioquímica de alimentos respectivamente.

Os ingredientes utilizados na produção da mousse foram: leite desnatado (UHT), creme de leite com $25 \%$ de gordura, gelatina em pó sem sabor, polpa de seriguela congelada, açúcar, leite em pó e pólen apícola. Todos os ingredientes foram adquiridos no comércio local.

\subsection{Elaboração do Produto}

Foram produzidas três formulações de mousses, sendo elas: (C) controle, sem adição de pólen apícola; (F1) com adição de $1 \%$ de pólen apícola; e (F2) com adição de $2 \%$ de pólen apícola. As proporções de cada ingrediente estão quantificadas na tabela.1.

Tabela 1: Elaboração do mousse de seriguela em 3 formulações diferentes Limoeiro do Norte-CE.

\begin{tabular}{|c|c|c|c|}
\hline \multirow{2}{*}{ Ingredientes } & \multicolumn{3}{|c|}{ Formulações (\%) } \\
\cline { 2 - 4 } & C1 & F1 & F2 \\
\hline Leite Integral UHT & 50 & 50 & 50 \\
\hline Creme de leite & 20 & 19 & 18 \\
\hline Polpa de seriguela & 15 & 15 & 15 \\
\hline Açúcar & 10 & 10 & 10 \\
\hline Leite em pó & 4 & 4 & 4 \\
\hline Gelatina em pó sem sabor & 1 & 1 & 1 \\
\hline Pólen Apícola & - & 1 & 1 \\
\hline Total & 100 & 100 & 100 \\
\hline
\end{tabular}

Fonte: Elaborada pelas autoras, 2018

Para a elaboração do mousse utilizou-se uma metodologia adaptada de Leal et al., (2009), onde os ingredientes foram pesados e mesclados, a mistura foi aquecida a $80-85^{\circ} \mathrm{C}$ em ba- 
nho-maria, exceto para o pólen apícola. Em seguida, o produto foi resfriado a $40{ }^{\circ} \mathrm{C}$, em banho de gelo, com agitação contínua, e logo que essa temperatura foi atingida o pólen apícola foi adicionado. Posteriormente, a mistura foi homogeneizada e aerada, utilizando-se batedeira convencional, até atingir a temperatura de $14^{\circ} \mathrm{C}$ e o volume dobrar.

$\mathrm{O}$ produto obtido foi embalado em embalagens plásticas, sendo armazenados em refrigerador doméstico a $5{ }^{\circ} \mathrm{C}$, até o momento das análises. Foram elaborados três lotes distintos de cada formulação.

\subsection{Caracterização Físico-Química}

As formulações do mousse foram submetidas às análises físico-químicas de umidade, cinzas, proteínas e lipídios, $\mathrm{pH}$, acidez, de acordo com os métodos oficiais (AOAC, 2005). Os carboidratos foram determinados por diferença, utilizando a fórmula: $\% \mathrm{CHO}$ totais $=100 \%$ - $(\%$ umidade $+\%$ cinzas $+\%$ proteínas $+\%$ lipídios). $\mathrm{O}$ valor energético total (VET) foi obtido pela conversão da quantidade em gramas de carboidratos, proteínas e gorduras para calorias, de acordo com a fórmula: $\mathrm{VET}=($ carboidratos $\times 4)+($ proteínas $\times 4)+($ lipídios $\times$ 9) $(\mathrm{CECCHI}, 2003$; BRASIL, 2005).

A vitamina $\mathrm{C}$ foi determinada pelo método colorimétrico com solução DFI (2,6 diclofenolindofenol 0,02\%) até a coloração rósea clara permanente, conforme descrito por Strohecker e Henning (1967). A análise de Polifenóis Extraíveis Totais foi realizada por espectofotometria utilizando o reagente Folin Ciocalteau e curva padrão de ácido gálico. Os resultados foram expressos em $\mathrm{mg}$ de fenólicos totais em equivalente de ácido gálico por grama de amostra, conforme descrito por Larrauri, Rupérez e Saura-Calixto (1997).

A análise de textura foi realizada através de um texturômetro modelo TA XT2i, Syable Micro System. A textura das amostras foi medida com uma velocidade de penetração de 2 $\mathrm{mm} / \mathrm{s}$, distância de penetração de $30 \mathrm{~mm}$ no tempo total de ensaio de $30 \mathrm{~s}$. A determinação da textura foi realizada em triplicata para cada formulação do mousse.

\subsection{Análise Estatística}

Todas as análises foram realizadas em triplicata e os resultados foram submetidos à análise de variância (ANOVA) e as médias comparadas entre si pelo teste de Tukey ao nível de 5\% de significância utilizando o programa Statistica 7.0 (STATSOFT, 2007).

\section{RESULTADOS E DISCUSSÃO}

Foram analisados proteína, lipídios, carboidratos, umidade e cinzas. A partir das análises realizadas foi determinada a composição centesimal de cada formulação de mousse. A tabela 2 apresenta os dados obtidos.

As formulações de mousse elaboradas não apresentaram valores expressivos de proteína, que também não diferiram estatisticamente entre si. Todavia esses valores aumentaram a medida que o pólen foi acrescentado. O pólen apresenta em sua composição valores elevados de proteína, o que enriquece o produto. De acordo com Modro et al. (2007), os grãos de pólen apresentam concentração proteica de 2,5 a $61 \%$, sendo assim considerando um alimento de alto valor proteico.

Valores de lipídios apresentaram um pequeno declínio com a adição de pólen, apresentando diferença estatística entre a amostra controle e as amostras com adição de pólen. Essa diminuição pode ser decorrente de uma oxidação maior dos compostos adicionados e/ou a diminuição do creme de leite, ingrediente rico em gordura.

Juliano et al. (2014), ao elaborar sobremesas lácteas tipo frozen, encontrou valores de lipídios em torno de $(2,65$ a 3,20) e essas concentrações são justificadas pela composição da sobremesa láctea, em que a matéria-prima principal é o leite.

A legislação brasileira não estabelece valor mínimo para sobremesas lácteas mas indica o valor mínimo de $2,5 \%$ de proteínas e de lipídios para gelados comestíveis e sorvetes (BRASIL, 1999), havendo ausência de padrões para os demais parâmetros. Desta forma a formulação controle estaria fora dos padrões estabelecidos e as formulações contendo pólen, estariam de acordo, se considerado o desvio padrão.

Não houve diferença significativa nos valores encontrados para carboidratos, podendo ser justificada pela composição dos ingredientes, onde nenhum ingrediente difere em conteúdo de carboidratos. Em comparação ao estudo realizado por Sousa, Brito e Farias (2016) que elaboraram mousses funcionais para pacientes com inflamação gástrica com adição de pólen apícola, o valor de carboidratos apresentado foi o dobro do que encontrado neste estudo $(40,95-43,23)$, podendo ser justificado pelos ingredientes encontrados na formulação.

Os valores para umidade foram próximos, mas ainda assim diferiram estatisticamente, onde se pode observar um pequeno declínio nas amostras enriquecidas. O conteúdo de umidade é alto, em torno de $70 \%$, podendo ser justificado por se tratar de uma preparação a base de leite e frutas, alimentos com um alto teor de água, o que o torna um produto de alta perecibilidade. Resultados semelhantes foram observados por Sousa, Brito e

Tabela 2. Composição Centesimal dos mousse de seriguela adicionado de pólen apícola.

\begin{tabular}{|c|c|c|c|}
\hline Composição Centesimal & Controle & Formulação F1 & Formulação F2 \\
\hline Proteína (\%) & $1,83 \mathrm{~A} \pm 0,16$ & $2,19 \mathrm{a} \pm 0,44$ & $2,43 \mathrm{a} \pm 0,75$ \\
\hline Lipídios (\%) & $5,45 \mathrm{a} \pm 0,24$ & $5,15 \mathrm{ab} \pm 0,04$ & $4,83 \mathrm{~b} \pm 0,02$ \\
\hline Carboidratos (\%) & $20,62 \mathrm{a} \pm 0,55$ & $21,32 \mathrm{a} \pm 0,80$ & $21,36 \mathrm{a} \pm 0,67$ \\
\hline Umidade (\%) & $71,20 \mathrm{a} \pm 0,35$ & $70,43 \mathrm{~b} \pm 0,35$ & $70,46 \mathrm{ab} \pm 0,15$ \\
\hline Cinzas (\%) & $0,90 \mathrm{a} \pm 0,03$ & $0,91 \mathrm{a} \pm 0,03$ & $0,92 \mathrm{a} \pm 0,03$ \\
\hline$*$ VET (Kcal/ 100g) & $138,87 \mathrm{a} \pm 0,96$ & $140,36 \mathrm{a} \pm 1,46$ & $138,64 \mathrm{a} \pm 0,82$ \\
\hline
\end{tabular}

Médias seguidas de letras iguais na mesma linha não diferem entre si significativamente quanto ao tratamento, segundo o teste de tukey $(\mathrm{p}>0,05)$ para as amostras de mousse.

*VET: Valor energético total. Fonte: Elaborada pelas autoras. 
Farias (2016), onde houve declínio de umidade da amostra adicionada de pólen $(44,23)$ para a amostra sem pólen $(42,51)$.

Valores de cinzas e VET (Valor energético total) não apresentaram diferenças significativas entre as formulações.

Outras análises realizadas nas formulações de mousses de seriguela estão descritas na tabela 3 com seus respectivos re- trados por Albuquerque et al., (2016), em cookies adicionados de seriguela. Em sua formulação controle (sem adição da seriguela), os autores encontraram um valor de $5,08 \mathrm{mg} / 100 \mathrm{~g}$ de vitamina $\mathrm{C}$ e 8,96 até 14,15 para os adicionados de seriguela. Isso mostra que o enriquecimento do produto com o fruto aumentou os níveis de vitamina $\mathrm{C}$.

Tabela 3. Análises físico-químicas dos mousses de seriguela adicionado de pólen apícola

\begin{tabular}{|c|c|c|c|}
\hline Parâmetros Físico-químicos & Controle & Formulação F1 & Formulação F2 \\
\hline $\mathrm{pH}$ & $5,60 \mathrm{~b} \pm 0,07$ & $6,42 \mathrm{a} \pm 0,13$ & $6,52 \mathrm{a} \pm 0,03$ \\
\hline Acidez (ácido lático/100g) & $6,52 \mathrm{a} \pm 0,03$ & $6,71 \mathrm{a} \pm 0,96$ & $6,47 \mathrm{aa} \pm 0,74$ \\
\hline Vitamina C (mg/100g) & $6,04 \mathrm{~b} \pm 0,00$ & $6,04 \mathrm{~b} \pm 0,00$ & $9,03 \mathrm{a} \pm 0,00$ \\
\hline $\begin{array}{c}\text { Compostos Fenólicos (mg } \\
\text { GAE*/g de amostra) }\end{array}$ & $18,83 \mathrm{~b} \pm 1,38$ & $42,60 \pm 2,33$ & $40,23 \mathrm{a} \pm 3,60$ \\
\hline
\end{tabular}

Médias seguidas de letras iguais na mesma linha não diferem entre si significativamente quanto ao tratamento, segundo o teste de tukey $(\mathrm{p}>0,05)$.

* GAE: Equivalente em ácido gálico. Fonte: Elaborada pelas autoras, 2018.

sultados.

No parâmetro $\mathrm{pH}$ pode-se observar que a amostra controle diferiu estatisticamente das amostras contendo pólen. Estas por sua vez não apresentaram diferença significativa entre si. Observou-se que os valores aumentaram de acordo com a quantidade do pólen adicionado na amostra, o que sugere que a presença do pólen influencia no que se refere ao valor de $\mathrm{pH}$.

Os valores encontrados para o mousse adicionado de pólen apícola foram próximos aos encontrados por Cruz e Pertuzatti (2014), em sobremesas lácteas de chocolate adicionado de baru $(6,45$ - 6,93), a amostra que não continha baru apresentou o maior $\mathrm{pH}$. Diferentemente do baru (Dipteryx alata), que diminuía o $\mathrm{pH}$ das sobremesas, o pólen proporciona um aumento desses valores. Silva et al., (2010), em um estudo com bebida láctea sabor bacuri enriquecida de pólen apícola, apresentaram resultados de $\mathrm{pH}$ variando de $(4,4-4,0)$, valores estes abaixo dos encontrados no presente estudo. Isso pode estar relacionado com a acidez do soro do leite, ingrediente primário da bebida láctea.

A acidez não apresentou diferença estatística significativa entre as amostras analisadas, mostrando que a adição do pólen não alterou a acidez final do produto, mas apresentou valores altos de acidez expressa em ácido lático, diferindo dos valores encontrados também por Silva et al. (2010) e Cruz e Pertuzatti (2014) que encontraram valores abaixo de 1.

No que se refere ao teor de vitamina $\mathrm{C}$, as formulações controle e F1 não apresentaram diferença entre si. A formulação 2, em que a porcentagem de pólen apícola foi maior se diferiu das demais, indicando que valores maiores de pólen apresentam maiores quantidades de ácido ascórbico, o que sugere um maior potencial antioxidante. Os valores de vitamina $\mathrm{C}$ podem também estar relacionados a utilização da fruta seriguela, por se tratar de uma fruta rica nesta substância.

Os valores de vitamina $\mathrm{C}$ forram semelhantes aos encon-
Em relação aos compostos fenólicos foram estes foram encontrados em todas as amostras analisadas, apresentando valores maiores nas amostras contendo pólen. Pegoraro (2011), analisou o pólen separadamente e verificou altos valores de compostos fenólicos, indicando que o pólen é um produto rico neste composto, sendo uma ótima fonte destes compostos antioxidantes.

Segundo Amácio et al., (2014), os polifenóis são poderosos antioxidantes, e no pólen são encontrados diversos tipos, dentre eles os flavonoides. Essa variedade de polifenóis é dada pelos inúmeros grãos diferentes que podem ser encontrados no pólen, que aumenta ainda mais seu poder antioxidante.

No que se refere à textura das amostras foram analisados os seguintes parâmetros: dureza, adesividade, coesividade e mastigabilidade. Os resultados estão expressos na tabela 5.

Dentre os parâmetros analisados apenas coesividade e mastigabilidade da formulação 2 apresentou diferença significativa das outras formulações. Todas as formulações apresentaram um valor alto de dureza de 475,56 N a 922,59 N, havendo um declínio com adição do pólen. Juliano et al. (2014), encontrou valores que variaram de $46,6 \mathrm{~N}$ a $498,4 \mathrm{~N}$. O autor relata que um alimento que apresenta uma maior resistência a penetração apresenta uma maior dureza, e que isso pode está relacionado ao estado de agregação dos glóbulos de gordura, da quantidade de ar incorporado, do tamanho e da quantidade dos cristais de gelo formados, e isso apresenta relação direta com toda matriz alimentícia da amostra.

Em relação ao item coesividade, eles apresentaram variação de 0,56 a 0,72. Oliveira e Benassi (2010), quando avaliaram pudins de diferentes marcas com açúcar e sem açúcar, obtiveram valores variando de 0,49 a 0,65 , e os pudins com adição de açúcar apresentaram maiores valores.

Em relação ao item coesividade, eles apresentaram variação de 0,56 a 0,72. Oliveira e Benassi (2010), quando avaliaram

Tabela 4. Resultados da análise Instrumental de Textura realizada nos mousses de seriguela adicionado de pólenapícola. Limoeiro do Norte -CE.

\begin{tabular}{|c|c|c|c|}
\hline Parâmetros de Textura & Controle & Formulação F1 & Formulação F2 \\
\hline Dureza (N) & $922,59 \mathrm{a} \pm 156,44$ & $785,55 \mathrm{a} \pm 141,57$ & $475,56 \mathrm{a} \pm 265,59$ \\
\hline Adesividade (N.mm) & $-100,55 \mathrm{a} \pm 62,81$ & $-160,08 \mathrm{a} \pm 72,51$ & $-92,72 \mathrm{a} \pm 39,50$ \\
\hline Coesividade & $0,70 \mathrm{a} \pm 0,02$ & $0,70 \mathrm{a} \pm 0,02$ & $0,56 \mathrm{~b} \pm 0,07$ \\
\hline Mastigabilidade (N.mm) & $537,41 \mathrm{a} \pm 74,83$ & $534,70 \mathrm{a} \pm 78,68$ & $251,76 \mathrm{~b} \pm 121,29$ \\
\hline
\end{tabular}

Médias seguidas de letras iguais na mesma linha não diferem entre si significativamente quanto ao tratamento, segundo o teste de tukey $(\mathrm{p}>0,05)$ para as amostras de mousse.

Fonte: Elaborada pelas autoras. 
pudins de diferentes marcas com açúcar e sem açúcar, obtiveram valores variando de 0,49 a 0,65 ,onde os pudins com adição de açúcar apresentaram maiores valores.

O parâmetro mastigabilidade apresentou diferença estatística significativa apenas para a formulação 2. Os valores variaram de 251,76 a 537,41.

De forma geral muitos dos parâmetros avaliados apresentaram diferença quando comparadas as formulações controle as adicionadas de pólen. Isso pode ser justificado pela composição do produto que muda bem como da composição do pólen adicionado.

\section{CONCLUSÕES}

Os dados físico-químicos e composição centesimal sugeriram que a adição de pólen, na quantidade utilizada; não modificou suas características, a não ser dos composto biotativos pois demonstrou aumento de compostos bioativos e vitamina $\mathrm{C}$.

No aspecto da textura percebeu-se que os parâmetros de coesividade e mastigabilidade modificaram com a adição a maior adição do pólen.

Com isso, temos que o produto elaborado com pólen apresenta potencial de alimento funcional pela presença de bioativos mas devem ser feitos estudo sensoriais principalmente de textura e sabor para perceber se a modificação feita é aceita por consumidores.

\section{REFERÊNCIAS BIBLIOGRÁFICAS}

AOAC. Official methods of analysis of the Association Analytical Chemists. 18 ed., Gaithersburg, Maryland, 2005. $771 \mathrm{p}$.

ALBUQUERQUE, J. G.; DUARTE, A. M.; CONCEIÇÃO, M. L.; AQUINO, J. S. Integral utilization of seriguela fruit (spondias purpurea 1.) In the production of cookies. Revista. Brasileira de. Fruticultura., v. 38, n. 3, 2016, p. 229.

AMÁCIO, D.; SERRANO, M.; ANJOS, O.; CAMPOS, O. Therapeutic potential of pollen. Planta Med. V.80, n.16, 2014. p2-37.

BARTH O. M; FREITAS A. S; OLIVEIRA E. S; SILVA R. A; MAESTER F. M, ANDRELLA R. R. S; CARDOZO, G. M. B. Q. Evaluation of the botanical origin of commercial dry bee pollen load batches using pollen analysis: a proposal for technical standardization. Anais da Academia Brasileira de Ciências, v. 84, n. 4, p. 893-902, 2010.

BRAGA, A. D. A.; BARLETA, V C. N. Alimento funcional: uma nova abordagem terapêutica das dislipidemias como prevenção da doença aterosclerótica. Cadernos UniFOA, v. 2, n. 3, p. 100-120, 2017.

BRASIL. Ministério da Agricultura e do Abastecimento. Instrução normativa $N^{\circ} 3$, de 19 de janeiro de 2001. Regulamentos Técnicos de Identidade e Qualidade de Pólen Apícola.
Diário Oficial da União da República Federativa do Brasil, Brasília, DF, 23 de janeiro de 2001, Seção 16-I, p. 18-23.

BRASIL Ministério da Saúde. Agência nacional de Vigilância Sanitária. Métodos Físico-Químicos para análises de Alimentos. $4^{\mathrm{a}}$ ed. Brasília: Ministério da Saúde, 2005. 1018p.

Brasil, Ministério da Saúde. Agência Nacional de Vigilância Sanitária. (1999). Regulamento Técnico Referente a Gelados Comestíveis, Preparados, Pós para Preparo e Bases para Gelados Comestíveis. (Portaria No 379, de 26 de abril de 1999). Diário Oficial da República Federativa do Brasil.

BURITI, F. C. A.; BEDANI, R.; SAAD, S. M. I. Probiotic and prebiotic dairy desserts. In: WATSON, R. R.; PREEDY, V. R. Probiotics, prebiotics and synbiotics. Amsterdam: Elsevier, 2016. p. 345-360.

CARPES, S. T.; PRADO, A.; MORENO, I. A. M.; MOURÃO, G. B.; ALENCAR, S. M.; MASSON, M. L. Avaliação do potencial antioxidante do pólen apícola produzido na região Sul do Brasil. Química Nova, v. 31, n. 7, p. 16601664, 2008.

CECCHI, H. M. Fundamentos teóricos e práticos em análise de alimentos. $2^{\mathrm{a}}$ ed. Campinas: Editora da UNICAMP, 2003. 208p.

CRUZ, P. N.; PERTUZATTI, P. B. Sobremesas lácteas sabor chocolate e baru (Dipteryx Alata Vogel): Desenvolvimento e Caracterização. XX Congresso Brasileiro de Engenharia Química. Florianópolis-SC, 2014. 8p.

ENGELS, C.; GRATER, D.; ESQUIVEL, P.; JIMENEZ, V. M.; GANZLE, M. G.; SCHIEBER, A. Characterization of phenolic compounds in jocote (Spondia purpurea L.) peels by ultra high-performance liquid chromatography/ electrospray ionization mass spectrometry. Food Research Internacional. v. 46, n.1., p. 557562, 2012.

JULIANO, R. S.; SARKIS, S. S. J.; PINHEIRO, A. C.; FEAR, A. C.; ZAMBELli, C. A.; AUGUSTO, M. M. Desenvolvimento de sobremesa láctea tipo frozen yogurt com características funcionais. XX Congresso Brasileiro de Engenharia Química. Florianópolis.SC, 2014.

LARRAURI, J. A.; RUPÉREZ, P.; SAURA-CALIXTO, F. Effect of drying temperature on the stability of polyphenols and antioxidant activity of red grape pomace peels. Journal of Agriculture and Food Chemistry. v. 45, n.4, p.1390-1393, 1997.

LEAL, C. L.; ARAGON, D.C.; COELHO, G. R.; DONATO, J. M.; SANTANA, E. H. W.; ARAGON-ALEGRO, L. C.; Potencial probiótico de mousse de manga elaborada com diferentes hidrocolóides. Revista do Instituto de Laticinios Cândido Tostes, v.64, n.371, p. 40-47, 2009. 
MARUYAMA, L. Y.; CARDARELLI, H. R.; BURITI, F. C. A.; SAAD, S. M. I. Textura instrumental de queijo petit suisse potencialmente probiótico: influência de diferentes combinações de gomas. Revista Ciência e Tecnologia de Alimentos. v. 26, n. 2, p. 386-93, 2006.

MODRO, A.F.H.; MESSAGE, D.; LUZ, C. F. P.; NETO, J. A. A. M. Composição e qualidade de pólen apícola coletado em Minas Gerais. Pesq. agropec. bras., Brasília, v.42, n.8, 2007. p.1057-1065.

OLIVEIRA, A. P. V.; BENASSI, M. T. Avaliação sensorial de pudins de chocolate com açúcar e dietéticos por perfil livre. Ciênc. Agrotec. v. 34, n. 1, 2010 p. 146-154.

PEGORARO, B., Desenvolvimento de um iogurte acrescido de geleia de amora preta (Morus nigra L.) e pólen apícola. Repositório Roca da Universidade Tecnológica Federal do Paraná - UTFP 2011. Disponível em: http://repositorio.roca.utfpr.edu. br/jspui/handle/1/261. Acesso em 02 de dezembro de 2018.

SILVA, E.V.C.; MEDEIROS, L. F. P. S.; MONTEIRO, D. B.; SILVA, G. F. Elaboração de bebida láctea pasteurizada sabor bacuri enriquecida com pólen. Revista Brasileira de Tecnologia Agroindustrial. v. 04, n.01, 2010, p.01-09.

SOUSA, D. M.; BRITO, M. M.; FARIAS, V. L. Elaboração de mousses funcionais para pacientes com inflamação gástrica. XXV Congresso Brasileiro de Ciências e Tecnologia de Alimentos. Gramado, 2016.

STROHECKER, R.; HENNING, H. M. Análises de vitaminas: métodos comprovados. Madrid: Paz Montalvo, 1967, 428p.

STATSOFT. (2007). Statistica for Window - Computer programa manual, Versão 7.0. Tulsa: Statsoft Inc.

TEIXEIRA, D. M. A.; BRAGA, R. C.; HORTA, A. C. G.; MOREIRA, R. A.; BRITO, A. C. F.; MACIEL, J. S.; FEITOSA, J. P. A.; PAULA, R. C. M. Spondias purpurea exudate polysaccharide as affinity matrix for the isolation of a galactose -binding- lectin. Carbohydrate Polymers, v. 70, s/n, p. 369-377, 2007.

XIMENES, L. J. F; COSTA, L. S. A. C; NASCIMENTO, J. L. S. N; Manejo racional de abelhas africanizadas e de meliponíneos no Nordeste do Brasil. Fortaleza: Banco do Nordeste do Brasil, 2011. 386p.

\section{AGRADECIMENTOS}

Agradecemos ao CNPq, CAPES e FUNCAP por bolsas auxílios recebidos. 